\title{
A PRESENÇA DE SIMMEL NA OBRA DE HABERMAS ${ }^{1}$
}

\author{
Bento Itamar Borges"
}

\begin{abstract}
RESUMO
Este artigo faz um levantamento das passagens em que Habermas cita Georg Simmel (1858-1918), pensador muito criativo e popular, mas preterido pela academia alemã. Autor de uma Filosofia do amor e de uma Filosofia do dinheiro, foi também o fundador da disciplina Filosofia da Cultura, que influenciou Adorno e Horkheimer, em suas teses sobre a cultura de massas. Ao reuni-lo com outros tantos filósofos judeus, que compuseram grande parte do idealismo alemão, Habermas aponta no antisemitismo um dos preconceitos que prejudicaram a carreira acadêmica de Simmel e sua recepção pelas gerações seguintes.
\end{abstract}

PALAVRAS-CHAVE: Habermas. Simmel. Filosofia alemã.

\begin{abstract}
This paper aims to collecting texts in which Habermas quotes Georg Simmel (1858-1918), a very creative and popular author, although rejected by German academic institutions. Besides having written two rare and apparently not related titles - a Philosophy of Love and a Philosophy of money -, he has founded a new discipline, the Philosophy of Culture, which influenced Adorno and Horkheimer in their thesis concerning mass culture. Habermas joined in a radio conference a large group of Jew philosophers among German intellectuals up to the post World War II period; this helps us to understand how such prejudices against Simmel, specially his racial

\footnotetext{
1 Texto originalmente apresentado na mesa-redonda "Simmel, Horkheimer e Habermas", na XII Semana de Filosofia, Uberlândia, DEFIL, UFU, 01 a 04 de setembro de 2008.

${ }^{*}$ Doutor em Filosofia pela Universidade Federal de Minas Gerais e Professor do Departamento de Filosofia da Universidade Federal de Uberlândia. E-mail: bentoib@gmail.com
} 
origin, had inhibited his career and the reception of his works.

KEYWORDS: Habermas. Simmel. German philosophy.

\section{Apresentação de Georg Simmel}

"Há três categorias de filósofos: uns escutam pulsar o coração das coisas, outros o dos homens, e os terceiros o dos conceitos. Há ainda um quarto grupo (o dos professores de filosofia) - que só escutam o coração dos textos."

(Georg Simmel)

Simmel nasceu em Berlim, no ano de 1858 e morreu em Strassburg, em 1918. Além disso, qualquer biografia curta pode citar, entre suas obras, uma Filosofia do amor, bem como uma Filosofia do dinheiro, o que insinua ainda hoje uma ampla variação de interesses, já que sempre supomos a linearidade sem saltos, na carreira acadêmica. Além disso, a frase em epígrafe parece sustentar a caricatura de um autor da linhagem de Schopenhauer, ou seja, um pensador genial, porém arredio aos trâmites do enquadramento pela instituição de ensino controlada por mandarins conservadores. Enciclopédias e biógrafos confirmam essa impressão, que Habermas também desenvolve, como relevante, em mais de uma ocasião. Ao que parece, a frase acima deve ter sido escrita antes de 1914, ano em que, finalmente, Simmel conseguiu um posto de professor regular. Só aos 56 anos e muito longe de Berlim, foi parcialmente aceito pela academia alemã, em Strassburg, onde viveria os últimos quatro anos de sua vida. Destacado para viver em uma cidade provinciana, na fronteira com a França, sofreria sem o meio urbano da metrópole onde nascera e com a qual sentia desenvolver-se. Preconceitos diversos fizeram com que ele ficasse fora do circuito acadêmico alemão, embora fosse contemporâneo de nomes reconhecidos como Bergson e Durkheim. Escreveu sobre Kant, Goethe, Rembrandt e diversos outros autores e temas. 
Só ao final do século XX foi ligeiramente restabelecido, inclusive como fundador da Filosofia da Cultura. ${ }^{2}$

\section{Comentário sobre a escrita compulsiva de Habermas}

Não se deve favorecer a imagem estereotipada de que Habermas, jovem ou maduro, tenha tido períodos de produção de obras de peso, mais especulativas e sistemáticas, e alguns intervalos, quando se ocupa de miudezas. Embora tenha ele assumido certos compromissos prioritários no Instituto Max Planck, por exemplo, não parece ter recusado convites para discursos de homenagem, como tampouco tem se furtado à cena política européia - aparece na mídia para defender uma Constituição para a Europa, para relativizar o "Onze de Setembro", para deplorar a guerra imperialista de Bush - embora houvesse considerado justificável, mas não justo, o primeiro ataque norte-americano, em resposta à agressão do Kuait pelo Iraque. É claro que os cadernos de cultura dos grandes jornais dão espaço até mesmo para recuperar um encontro acadêmico entre Habermas e seu conterrâneo bávaro Bento XVI, quando ainda se apresentava como Joseph Ratzinger.

Um exemplo dessa capacidade de manter agendas cheias e paralelas é que a conferência radiofônica, apresentada em 1961, sobre os filósofos judeus, foi preparada no mesmo ano de defesa de sua tese de doutorado. E nesse mesmo ano saiu o volume da pesquisa sociológica, feita em equipe, Estudante e política [Student und Politik], além de haver escrito alguns dos ensaios e conferencias que comporiam o volume Teoria e prática [Theorie und Praxis, de 1963]. Em uma conferência, aliás excepcionalmente bonita e animadora, pronunciada no parlamento espanhol em 1984, Habermas anuncia que trata de outros temas, além daqueles para os quais é pago, como então, ao falar sobre - e, em certa medida, contra - o "esgotamento das energias utópicas", ou seja, a "perda de confiança em si mesma da cultura ocidental". ${ }^{3}$

\footnotetext{
${ }^{2}$ Mais sobre a biografia de Simmel, In: STECHER, Heinz. Georg Simmel: dinheiro, a solidez do efêmero. Cad. CRH, Salvador, n.22, jan/jun. 1995, p. 185-191 <www. cadernocrh.ufba.br/include/getdoc.php?id $=1425 \&$ article $=327 \&$ mode $=$ pdf $>$

3 "Sobre la perdida de confianza en si misma de la cultura occidental", Discurso de Habermas no parlamento espanhol, publicado pela casa em sua Revista de las cortes
} 


\section{Perfil de Simmel, um dos filósofos judeus}

A primeira edição da coletânea Perfis filosófico-políticos, em 1971, trouxe textos escritos por Habermas a partir de 1953. A segunda edição, de 1980, acrescentou novas páginas do gênero, produzidas até aquele ano. Os autores retratados são Plessner, Bloch, Karl Löwith, Wittgenstein, Wolfgang Abendroth, Walter Benjamin, Scholem, Gadamer, Alfred Schütz, Horkheimer, Löwenthal. Além desses, alguns autores mereceram mais de um perfil: Heidegger, Gehlen, Adorno, Mitscherlich e Hannah Arendt aparecem duas vezes, enquanto são dedicados três textos a Jaspers e quatro a Marcuse.

Dos dezenove autores apresentados e, em geral homenageados, no sentido corrente do termo, a edição francesa traz oito (Gallimard, 1974), a partir da primeira edição alemã, que tinha repertório menor. Curiosamente, essa edição francesa contém três textos sobre Heidegger - um a mais que a edição original, o que já manifestava o interesse dos franceses por Heidegger.

Uma das primeiras obras de Habermas publicadas no Brasil (Ática, 1980) é justamente uma versão curta desses perfis. Bárbara Freitag e Rouanet traduziram seis perfis, da primeira edição alemã. A seleção dos nomes de Hannah Arendt, Scholem, Marcuse, Adorno, Bloch e Benjamin foi feita, todavia, pelo próprio Habermas, que redigiu um prefácio especial "ao leitor brasileiro", justificando suas escolhas, ao mesmo tempo em que prestigia o gênero ensaio: os cinco filósofos, bem como o teólogo Scholem, conheceram-se pessoalmente e travaram também importantes polêmicas. Além disso, todos se definiram de alguma maneira, em torno de Benjamin e, além disso, todos tiveram que deixar a Alemanha, voltando depois da Guerra, "senão em pessoa, pelo menos através de publicações prestigiosas".

Para a constelação de autores reunidos na coletânea de perfis, interessa ainda registrar que, tanto a edição francesa, quanto a brasileira, fizeram bem ao incluir o primeiro dos textos na versão original, que não trata propriamente de uma figura específica, mas, sim, de uma corrente subterrânea, um perfil coletivo, portanto, sob o título de "O idealismo

generales, 1984, n. 3, p. 7-24. 
alemão dos filósofos judeus" (1961). É justamente nesse ensaio histórico - originalmente uma conferencia radiofônica - que Simmel aparece citado quatro vezes. Fora isso, em toda a obra dos Perfis, quase 500 páginas, Simmel aparece de relance apenas na homenagem feita a Gershom Scholem.

Habermas inicia o ensaio sobre os filósofos judeus, citando uma frase preconceituosa de Ernst Jünger, típica do anti-semitismo, sobre o judeu, que "não pode desempenhar qualquer papel criador na vida alemã". Habermas não refletira o bastante, quando estudante, sobre o conteúdo maldoso de frases como aquela, embora já tivesse lido Husserl, Wittgenstein, Scheler e Simmel, sem se dar conta da origem deles. Habermas quer mostrar como mesmo o Idealismo alemão, normalmente associado ao protestantismo, pode ser esclarecido a partir da experiência da tradição judaica, inclusive a cabalística. Todavia, para muitos judeus, que lutavam por sua assimilação à cultura e à sociedade alemãs, o dilema era justamente negar sua origem, pois no mundo acadêmico, davam preferência à epistemologia e à teoria da ciência, disciplinas tidas por a-históricas e isentas de pressupostos; a liberdade de pensamento era conquistada ao preço da renúncia à tradição.

Houve uma geração de kantianos judeus, que caiu no esquecimento, bem como o próprio Kant. E foi de um judeu, Otto Liebmann, a convocação - "É preciso voltar a Kant" - que abriu espaço para um segundo kantismo, em meados do século XIX, sob a condução de Cohen, que veio a ser professor de Cassirer. Além dessa orientação kantiana, que reforçou a dedicação à epistemologia, lembra Habermas que os judeus treinaramse nas técnicas exegéticas para a análise e o comentário, por meio da hermenêutica rabínica e da cabalística das Escrituras. Daí que "não é por acaso que Simmel, em sua Introdução à filosofia, utiliza a mística do mestre Eckart como chave para a compreensão da revolução copérnica de Kant". ${ }^{4}$

O classicismo alemão e, sobretudo, a interiorização do espírito de Goethe contribuíram, como necessidade vital, para a assimilação dos judeus, que, de certa forma, retribuíram com refinadas reflexões estéticas: "de

${ }^{4}$ HABERMAS, Jürgen. O idealismo alemão dos filósofos judeus, in Habermas: sociologia; trad. Bárbara Freitag e S. P. Rouanet. São Paulo: Ática, 1980, p. 83.

Educ. e Filos. Uberlândia, v. 23, n. 46, p. 247-262, jul./dez. 2009. 
Rosenkranz e Simmel a Benjamin, Lukács e Adorno". ${ }^{5}$ Uma das grandes contribuições de Walter Benjamin, a alegoria, oriunda da tradição cabalística, já havia causado impacto em sua tese sobre o drama barroco e em suas teses para uma filosofia negativa da história; em resumo, o inquieto pensador que refez o percurso urbano de Baudelaire, falou de anjos, de prostitutas e de figos maduros, escapando ao círculo de ferro da Teoria do Conhecimento. Mas não foi o primeiro nisso, pois antes dele, Simmel - amigo de Rilke, de Bergson e de Rodin - já havia ultrapassado "os limites das filosofias acadêmicas então hegemônicas". ${ }^{6} \mathrm{E}$ é certo que também transitava pelas fronteiras tênues entre a sociologia e uma antropologia que compreende o homem a partir dos papéis que tem necessariamente que desempenhar.

Simmel interessa também para a reconstrução da história do pensamento sociológico. Ao que parece, a cidade de Frankfurt, segundo Habermas, tem a capacidade de transformar filósofos e místicos em sociólogos, o que aconteceu até mesmo com Martin Buber. E, se é sabido que o espírito judeu dominou também na Sociologia alemã, deve-se reconhecer que o dinheiro sempre inflamou os pensadores judeus, dos quais Marx é o exemplo mais notável. Também Simmel, filho de um comerciante, como tantos outros reunidos no ensaio de Habermas, não resistiu e escreveu uma Filosofia do dinheiro, eivada de filosofia da natureza e de misticismo, com intenções muito distantes do economicismo estreito: "Tratar não somente todos os homens, mas também todas as coisas como se fossem fins em siseria uma ética cósmica"?

\section{Simmel, em obras mais sistemáticas de Habermas}

Max Weber recorrera à Filosofia do dinheiro, para informarse sobre a mudança de cenário, quando relações comunicativas naturais são traduzidas pela "linguagem universal do dinheiro". Esta passagem de Teoria do agir comunicativo, encontra-se no capítulo IV do volume I,

\footnotetext{
${ }^{5}$ Ibidem, p.; 89

${ }^{6}$ Ibidem, p. 90

${ }^{7}$ HABERMAS, Jürgen. O idealismo alemão dos filósofos judeus, in Habermas: sociologia; trad. Bárbara Freitag e S. P. Rouanet. São Paulo: Ática, 1980, p. 94
} 
"De Lukács a Adorno - a racionalização como coisificação". ${ }^{8} \mathrm{Na}$ mesma obra, volume II, Simmel reaparece em capítulo dedicado a "Talcott Parsons: problemas de construção da teoria da sociedade". Em parte da argumentação, Habermas reconhece a fraqueza de Parsons no apelo ao modelo kantiano de sujeito transcendental do conhecimento, inviabilizado, inclusive porque "desde Simmel e Max Adler esse modelo penetrou na teoria da sociedade apenas para trazer confusão às formas neokantianas e fenomenológicas de sociologia compreensiva provenientes de Rickert e de Husserl"..

Pode parecer surpreendente que não haja nenhuma referência de Habermas a Simmel em Direito e democracia (1992), que é sua obra de despedida da academia, a versão "institucional" e politicamente compromissada do paradigma discursivo, desenvolvido depois de demoradas pesquisas interdisciplinares. Simmel continuou ausente em $A$ inclusão do outro (1996), em que Habermas continua a conversa sobre direitos humanos e democracia e lança complementos a Direito e democracia. Ao que parece, depois de enfrentar essa grande "montanha", como se referiu à obra em entrevista, Habermas voltou a retratar filósofos, em textos curtos, pequenas colinas, como aquelas reunidas em Vom sinnlichen Eindruck zum symbolischen Ausdruck (Da impressão sensivel à expressão simbólica) de 1997, com novos perfis de Jaspers e Scholem, além de outros, retratados pela primeira vez, tais como von Wright, Apel, Metz, Theunissen e Alexander Kluge. Mas, eis que Simmel reaparece em recentíssima obra de Habermas, sobre tema um pouco inesperado, Entre Naturalismo e religião, de 2005, que teve tradução imediata no Brasil (Editora Tempo Brasileiro, 2007). Na terceira parte da obra, dedicada aos temas "Naturalismo e religião", há uma seção dedicada a Adorno, sobre o entrelaçamento de razão e natureza. Eis o plano do capítulo:

${ }^{8}$ HABERMAS, Jürgen. Teoría de la acción comunicativa. Trad. Manuel J. Redondo. Madri: Taurus, 1987, vol I, p. 457.

${ }^{9}$ HABERMAS, Jürgen. Teoría de la acción comunicativa. Trad. Manuel J. Redondo. Madri: Taurus, 1987, vol. 2, p. 366. 
Em primeiro lugar, Adorno introduz com o conceito de pseudoracionalidade a causalidade social de uma liberdade retida, reprimida e expulsa fora da consciência. Depois radicaliza a liberdade cotidiana convertendo-a na emancipação extra-cotidiana frente às relações pseudo-naturais e selvagens. Finalmente, restringe a causalidade natural dos estados que se sucedem segundo leis [...] ao âmbito de objetos da ciência da natureza que opera mediante explicações causais. ${ }^{10}$

É nessa terceira etapa que Habermas cita Simmel, que havia impressionado Adorno com sua "filosofia da vida". Simmel é o autor do conceito de uma "segunda natureza", conforme expressão de Lukács, em sua Teoria do romance: "é um complexo de sentido paralisado, alienado, que já não desperta a interioridade". Adorno interpreta essa passagem como a vingança do destino contra a sociedade moderna. A Dialética do esclarecimento completa esse pensamento: a lembrança da natureza no sujeito deve liberar o olhar para os começos arcaicos. $\mathrm{O}$ atropelo da história natural é conseqüência de uma razão instrumental que embrutece o processo de tornar disponível a natureza objetivada. ${ }^{11}$

\section{Simmel, um contraponto na crítica de Habermas aos pós-modernos}

Para entendermos os ataques de Habermas, com sua metralhadora giratória, no volume de O Discurso Filosófico da Modernidade, é necessário lembrar que, um pouco antes das quatro conferências no Collège de France, Habermas já havia sido provocado pelo francês Lyotard, que publicara $A$ condição pós-moderna, em 1979. Segundo seu critério, ele mesmo seria um pós-moderno, por não acreditar mais em grandes discursos, ao passo que Habermas ainda bancava o moderno, pois comprometia-se com grandes e pesadas conversas, tais como "emancipação". Logo em seguida, em 1980, ao receber o Prêmio Adorno, Habermas o agradeceu, com a leitura de um

${ }_{10}$ HABERMAS, Jürgen. Entre naturalismo y religión. Frankfurt sobre o Meno, Suhrkamp, 2005, p. 201

${ }^{11}$ HABERMAS, Jürgen. Entre naturalismo y religión. Frankfurt sobre o Meno, Suhrkamp, 2005, p. 205-206 
texto, em tom de manifesto: "A modernidade, um projeto inacabado". ${ }^{12}$ Pouco depois, em 1983, ao retornar a Frankfurt como Professor, depois de dez anos no Instituto Max Planck, em Starnberg, ofereceu dois semestres sobre o tema, "na esteira da recepção do neo-estruturalismo francês"; estava clara sua intenção de encarar o desafio posto pela crítica da razão efetuada pelo neo-estruturalismo. Habermas dispôs-se a reconstruir passo a passo o Discurso Filosófico da Modernidade. Para isso, começou pelos alemães: Hegel, os hegelianos de esquerda e de direita, Nietzsche e Heidegger, além de excursos sobre Benjamin e Schiller.

Há uma conferência especial dedicada aos riscos oriundos da parceria entre Adorno e Horkheimer, a propósito do estranho namoro entre "mito e esclarecimento", sobre a qual não vamos nos estender aqui. ${ }^{13} \mathrm{E}$, em seguida, vem a artilharia contra os franceses da hora, bem como estrangeiros naturalizados: Foucault (alvo de duas conferências), Derrida, Bataille, Castoriadis e alguns outros franceses tangenciados ou lembrados em notas de rodapé. Quatro conferências aconteceram no Collège de France, seis, nos EUA, e dois capítulos foram artigos pertinentes, anexados.

A leitura das conferências de O Discurso Filosófico da Moderidade pode causar um efeito devastador para mestrandos que procuram um autor ou um orientador, pois Habermas parece esforçar-se demais, de um modo que o torna, além de difícil, antipático. Mas, nos bastidores do Collège de France e nas atas de seu departamento de filosofia foi possível localizar um pouco do confronto de vaidades, no caso de Foucault que, lamentavelmente, viveria apenas por alguns meses depois. Quanto a Derrida, apesar e acima

\footnotetext{
${ }^{12}$ HABERMAS, J. La modernité: un projet inachevé (A modernidade : um projeto inacabado) Critique - revue generale des publications françaises et etrangeres. Paris : Ed. de Minuit, tomo XXXVII, n. 413, out. 1981.

${ }^{13} \mathrm{O}$ presente texto foi, antes, uma comunicação em uma mesa-redonda dedicada à filosofia alemã, em que Marcos Seneda trataria de Simmel, Rafael Cordeiro Silva exporia algo sobre Horkheimer e o autor deste texto se encarregaria de Habermas. Ao contrário da apresentação e da discussão que se seguiu, o autor deste texto não se dedicará a Horkheimer, pois as obras em que Habermas critica seus mestres Adorno e Horkheimer já estão suficientemente conhecidas e disponíveis também em português. Cf. o capítulo V de $O$ Discurso Filosófico da Moderidade e HABERMAS, Jürgen. Observações sobre o desenvolvimento da obra de Max Horkheimer; trad. Maurício Chiarello. Educação e filosofia, Uberlândia, v. 21, n. 42, p. 272-293, jul./dez. 2007
} 
de todas suas diferenças teóricas, a interlocução com Habermas continuou, pelo menos diante de episódios como " $O$ Onze de Setembro" e a formação do bloco Europa. O livro só não nos soa mais "irritante" porque Habermas incluiu dois capítulos, os finais, onde apresenta a sua própria receita: como salvar o projeto moderno da razão, mediante a conversão ao paradigma discursivo. Por fim, como despedida, desferiu mais alguns golpes contra o velho adversário e conterrâneo Niklas Luhmann.

A confiar em nossa atenção durante a demorada leitura e no índice remissivo da edição francesa de $O$ Discurso Filosófico da Moderidade, ${ }^{14}$ Simmel figura três vezes e, felizmente, em todas elas, fora da linha de tiro dessa obra um tanto zelosa e eventualmente agressiva. A primeira ocorrência está no sexto capítulo, intitulado "A corrosão crítico-metafísica do racionalismo ocidental: Heidegger". Habermas não se convence da "altiva exigência" do autor de Ser e tempo - renovar a pergunta pelo significado do esquecido Ser - e prefere colocar o projeto editorial no cruzamento do pósidealismo do século XIX com uma recaída neo-ontológica que acometeu a filosofia alemã depois da Primeira Guerra, como em Rickert, Hartmann e Scheler. Não era mais exatamente uma ontologia kantiana, pois já se podia dispor de explorações feitas pelo historicismo e pela filosofia da vida nos domínios da experiência cotidiana ou extra-cotidiana, que minavam o sujeito transcendental. Segundo Habermas,

Dilthey, Bergson e Simmel tinham substituído as produções da síntese transcendental pela produtividade da vida ou da consciência, produtividade essa pouco clara e com um toque vitalista; de fato esses autores ainda não se tinham libertado do modelo expressivista da filosofia da consciência. ${ }^{15}$

Não nos cabe aqui garimpar uma avaliação geral da opinião de Habermas sobre a "filosofia da vida", mas é relevante reconhecermos que Simmel contribua com Heidegger, que avançou, até certo ponto, na tarefa

14 HABERMAS, Jürgen. Le discours philosophique de la modernité : douze conférences. Gallimard [1988]

15 HABERMAS, Jürgen. O Discurso Filosófico da Modernidade; trad. Ana M. Bernardo e outros. Lisboa: Dom Quixote, 1990, p. 140 
de dissolução do sujeito transcendental, embora não tenha conseguido superar o paradigma da consciência e algumas posições equivocadas diante da modernidade.

Novamente, no capítulo IX, "As ciências humanas desmascaradas pela crítica da razão: Foucault", Habermas volta a reunir o mesmo trio acima, na mesma rubrica da "filosofia da vida":

Como outrora em Bergson, Dilthey e Simmel, a "vida" foi elevada à categoria de conceito básico transcendental de uma filosofia, que constituía ainda para Heidegger o plano de fundo da sua análise do existente, também Foucault eleva agora o "poder" à categoria de conceito básico histórico-transcendental de uma historiografia da crítica da razão. ${ }^{16}$

A diferença aqui é que o contraponto gerado entre "vida" e "poder" pesa contra Foucault, pois, para o autor de Microfisica do poder, trata-se sempre de um poder repressivo, que se dissemina por instituições totais, sem brecha para a contestação e o diálogo racional entre as partes. Diferentemente de Derrida, que sofreu influência direta de Heidegger, a descrença de Foucault deve ser buscada em sua filiação a Nietzsche, através de Bataille. E é claro, afirma Habermas, que em Nietzsche, o poder é um conceito absolutamente não-sociológico. Por outro lado, há motivos socialmente explicáveis para a recepção de Nietzsche no projeto não apenas acadêmico de Foucault: vivia-se na França de 1968 um sentimento de desilusão com a fracassada revolta estudantil. Por esses e outros motivos é que Habermas diversas vezes se queixa do quanto são irritantes tais conceitos enviesados e até mesmo mascarados de bom-mocismo diante de setores da esquerda e da academia, que não quiseram levar adiante a verdadeira discussão teórica.

Ao final do décimo-primeiro capítulo, em que Habermas finalmente expõe seu paradigma, como alternativa à filosofia do sujeito, temos um oportuno excurso sobre Cornelius Castoriadis, intelectual turco-francês que marcou presença no cenário do debate político nos anos 1980. Já no corpo do capítulo, Habermas referiu-se a ele em curiosa associação com

${ }^{16}$ HABERMAS, Jürgen. O Discurso Filosófico da Modernidade; trad. Ana M. Bernardo e outros. Lisboa, Dom Quixote, 1990, p. 239 
Simmel, para mostrar como, apesar de avançar além da visão expressivista da linguagem, em favor de uma certa concepção poético-demiúrgica, Castoriadis permaneceu no lado errado nessa construção do Discurso Filosófico da Modernidade, sem alcançar o novo paradigma que superou a contemplação monológica: "Castoriadis termina como Simmel começou: com a filosofia da vida". ${ }^{17}$

\section{Habermas apresenta reedição de Simmel}

"Simmel enquanto diagnosticador dos tempos" seria uma boa tradução para o título original de um posfácio escrito por Habermas, em 1983, para a edição de uma coletânea de ensaios de Simmel, que, por sua vez, continha em seu título a expressão "crise da modernidade". Ao ser reeditado por Habermas no volume Texte und Kontexte (Textos e contextos), de 1991, o título mudou para "Georg Simmel sobre filosofia e cultura: posfácio para uma coletânea de essays", que foi mantido literalmente na tradução de Mathieu Deflem, aqui utilizada. ${ }^{18}$

Habermas avaliará, ao final de seu artigo, a curiosa situação de um autor rejeitado pela academia, que, ao ter suas principais obras reeditadas somente sessenta anos depois, afigura-se ao mesmo tempo como próximo e distante de nós: uma de suas obras principais, Filosofia do dinheiro (1900), reapareceu nas livrarias alemãs só em 1989. ${ }^{19}$

É difícil explicar o desaparecimento de Simmel, sobretudo no período que se seguiu ao fim da Segunda Guerra, se o compararmos, como faz Habermas, a Dilthey e a Bergson, que, com ele, iniciaram a Filosofia da vida; na virada do século, Simmel tinha sido tão influente nessa corrente, como o foi no campo da sociologia. Simmel era da mesma geração que Durkheim e Mead, os pais-fundadores da sociologia. Simmel não estava

${ }_{17}$ HABERMAS, Jürgen. O Discurso Filosófico da Modernidade; trad. Ana M. Bernardo e outros. Lisboa, Dom Quixote, 1990, p. 294

${ }^{18}$ HABERMAS, Jürgen. Georg Simmel on Philosophy and Culture: Postscript to a Collection of Essays. Critical Inquiry, n. 22, Primavera, 1996 (Traduzido por Mathieu Deflem, de HABERMAS, Jürgen. Texte und kontexte.Frankfurt, Suhrkamp, 1991)

${ }^{19}$ Edição inglesa: The philosophy of money; tradução de Tom Bottomore e Frisby. Londres, 1990. 
predestinado a ser um "clássico", por causa de sua orientação intelectual. Mesmo se reconhecermos sua importância em vários campos, em alguns dos quais foi pioneiro, devemos admitir que ele fosse mais criativo que sistemático. Por essa e outras razões, a academia viu nele um filósofo com uma queda pela ciência social, capaz de diagnosticar sua época, mas não um filósofo ou um sociólogo de carreira. Habermas tenta explicar que, acima de desencontros, como a recusa de sua dissertação em psicologia musical e de sua tese de pós-doutorado - que estaria fora do tema -, havia motivos ideológicos, como sua atitude relativista em relação ao Cristianismo, sua maneira pouco ortodoxa de pensar e aparentemente provocante de ensinar, bem como a inveja que despertava por causa de seu sucesso com os estudantes e com o público mais amplo. E, é claro, tudo piorava sob a onda de anti-semitismo e por causa do ressentimento devotado pela academia aos "intelectuais literários".

Mesmo Adorno, que defendeu o gênero ensaio e que reconheceu em Simmel o primeiro a conseguir levar a filosofia a temas concretos, irritava-se com os títulos que este dava a seus escritos. Habermas, que também entrevê um certo vacilo de Simmel, a balançar entre o ensaio e o tratado cientifico, vai todavia mais fundo ao localizar a raiz de nossa diferença em relação a ele:

É a noção neokantiana de cultura que assinala o que nos separa de Simmel. Ele é um filho do fin de siècle; ele ainda pertence àquela época formada intelectualmente quando Kant e Hegel, Schiller e Goethe eram contemporâneos - contemporâneos, na verdade, que já tinham sido colocados na sombra por Schopenhauer e Nietzsche. ${ }^{20}$

Simmel, que era amigo de Rodin, tentou explicar a vitória do escultor sobre o classicismo e o naturalismo, mas ainda operava com categorias estéticas de Kant e Schiller: liberdade e necessidade, espírito e natureza, forma e substância. Sob tais influências do romantismo tardio, Simmel não conseguiu reconhecer a antecipação da pintura expressionista. Por outro lado, causou impacto no jovem Lukács e influenciou Walter

${ }^{20}$ HABERMAS, Jürgen. Georg Simmel on Philosophy and Culture: Postscript to a Collection of Essays. Critical Inquiry, n. 22, Primavera, 1996, p. 407 
Benjamin, inclusive ao escrever sobre moda e modernidade. Com um pé no "historicamente esclarecido século XIX", esse intelectual profundamente urbano deve seu vigor ao diagnóstico das épocas, fundado na filosofia da cultura, disciplina que ele desenvolveu pela primeira vez ao final de A filosofia do dinheiro. Ele conseguiu também ser influente com uma descrição fenomenologicamente precisa do estilo de vida moderno, como nesta passagem: "O processo de objetivação da cultura, que... realiza um grande estranhamento entre o sujeito e seus produtos invade, por fim, os mais íntimos aspectos de nossa vida cotidiana". ${ }^{21}$ Se isso soa familiar aos leitores da teoria crítica, é justamente porque Adorno e Horkheimer adotaram teses de Simmel para esboçar a noção de cultura de massas, na Dialética do Esclarecimento.

A última parte do ensaio de Habermas aqui examinado parece ter sido acrescentada ou reescrita, sob influência do debate que travava com os ideólogos "neo-conservadores" do pós-modernismo:

A partir dessa conseqüência [a aceitação dos males do capitalismo como efeitos colaterais de um processo de racionalização do sistema social, por Gehlen e Luhmann] revela-se que os fenômenos dolorosos que um dia incendiaram o discurso da modernidade desaparecem, no fim das contas, sem deixar rastros, a não ser que, em vez de deixarmos tudo no esquecimento, revisemos os conceitos fundamentais da filosofia da vida, suas perspectivas de reconciliação e seu ideal expressivista de educação. ${ }^{22}$

Daríamos um final enfático - mas pouco honesto - se encerrássemos com esta citação um trabalho de garimpo na obra de Habermas, no qual os holofotes deveriam ser dirigidos a Simmel. Esse pensador inquieto e de sorte intermitente surpreende-nos mais uma vez, pois eis que nos aparece, ao final da exposição de Habermas, como um ousado e precoce defensor da causa das mulheres: em nome da dignidade de toda a humanidade sem exclusividade, nem prerrogativas para os machos. Em que pese algum

${ }^{21}$ Apud Habermas, in HABERMAS, Jürgen. Georg Simmel on Philosophy and Culture: Postscript to a Collection of Essays. Critical Inquiry, n. 22, Primavera, 1996, p. 410

22 Ibidem, p.412 - 413 . 
viés masculino bem intencionado, Habermas previa o reconhecimento dessa antecipação de Simmel. E é nesse sentido que Simmel está perto de nós, embora sua obra tenha passado por injustas peripécias, sobretudo na academia, que quis mantê-lo à distância.

\section{Referências}

ENZYKLOPÄDIE der Philosophie. Augsburg, Weltbild Verlag, 1992.

HABERMAS, Jürgen. Entre naturalismo y religión. Frankfurt sobre o Meno, Suhrkamp, 2005

HABERMAS, Jürgen. Georg Simmel on Philosophy and Culture: Postscript to a Collection of Essays. Critical Inquiry, n. 22, Primavera, 1996 (Traduzido por Mathieu Deflem, de HABERMAS, Jürgen. Texte und kontexte.Frankfurt, Suhrkamp, 1991)

HABERMAS, Jürgen. Habermas: sociologia; trad. Bárbara Freitag e S. P. Rouanet. São Paulo: Ática, 1980. (Grandes cientistas sociais)

HABERMAS, Jürgen. O Discurso Filosófico da Modernidade; trad. Ana M. Bernardo e outros. Lisboa: Dom Quixote, 1990.

HABERMAS, Jürgen. Observações sobre o desenvolvimento da obra de Max Horkheimer; trad. Maurício Chiarello. Educação e filosofia, Uberlândia, v. 21, n. 42, p. 272-293, jul./dez. 2007 (SCHMIDT, Alfred e ALTWICKER, N. Max Horkheimer heute: Werke und Wirkung. Frankfurt sobre o Meno, Fischer, 1986, p. 163-179)

HABERMAS, Jürgen. Teoría de la acción comunicativa. Trad. Manuel J. Redondo. Madri: Taurus, 1987, 2 vol.

STECHER, Heinz. Georg Simmel: dinheiro, a solidez do efêmero. Cad. CRH, Salvador, n.22, jan/jun. 1995, p. 185-191 Disponível em: www. cadernocrh.ufba.br/include/getdoc.php?id=1425\&article $=327 \&$ mode $=$ pdf. Acessado em 13 set 2008.

Data de registro: $17 / 09 / 08$

Data de aceite: 17/10/08

Educ. e Filos. Uberlândia, v. 23, n. 46, p. 247-262, jul./dez. 2009. 
